\title{
Inhibitory Effect of Ginsenoside-Rp1, a Novel Ginsenoside Deriva- tive, on the Functional Activation of Macrophage-like Cells
}

\author{
Tae Yoon PARK ${ }^{2}$ and Jae Youl $\mathrm{CHO}^{1,{ }^{*}}$ \\ ${ }^{1}$ School of Bioscience and Biotechnology, and Institute of Bioscience and Biotechnology, \\ Kangwon National University; Chuncheon 200-701, Republic of Korea \\ ${ }^{2}$ CAmbo Institute, 467-17 Dogok-dong, Gangnam-ku, Seoul 135-535, Republic of Korea
}

(Received August 19, 2008; Revised October 30, 2008; Accepted November 7, 2008)

\begin{abstract}
Ginsenoside Rp1 (G-Rp1) is a ginseng saponin derivative with chemopreventive and anti-cancer activities. In this study, we examined the regulatory activity of G-Rp1 on the functional activation of macrophages. G-Rp1 remarkably inhibited TNF- $\alpha$ production, LPS-induced cell cytotoxicity, NO production, ROS generation, and phagocytic uptake from lipopolysacchride (LPS)-activated RAW264.7 cells. According to structural feature study using several G-Rp1 analogs, two carbohydrates (glucose-glucose) at R1 position were observed to be highly effective, compared to other structural derivatives. Although the inhibitory activities of G-Rp1 on macrophage functions were not remarkable, several points that G-Rp1 was known to be safe, and that this compound was orally effective, suggest that G-Rp1 may be beneficial in treating macrophage-mediated immunological diseases.
\end{abstract}

Keywords: Ginseng saponin, Macrophage function, RAW264.7 cells, Immunological disease, Inflammation

\section{INTRODUCTION}

Macrophages are a type of differentiated tissue cells that originate from blood monocyte. The cells have several functions such as 1) killing the pathogenic microorganisms; and 3) the phagocytic uptake and processing/ presentation of antigens ingested to lymphocytes (Kinne et al., 2000). Therefore, the activation of macrophages is a key event for effective innate and adaptive immunity. When the body is stimulated by pathologic stimuli or injury, macrophages release 1) numerous pro-inflammatory cytokines [eg. tumor necrosis factor (TNF)- $\alpha$, and interleukin (IL)-1]; 2) cytotoxic and inflammatory molecules [e.g. nitric oxide (NO), and reactive oxygen species (ROS)]; and 3) phagocytic uptake of infected microorganisms (Plenz and Robenek 1998). These beneficial effects, however, are critically dependent on the magnitude of the host immune response, because large amounts of macrophage-derived inflammatory mediators can cause collateral or severe damage linked to inflammatory diseases such as septic shock, rheumatoid arthritis and arteriosclerosis

\footnotetext{
${ }^{*}$ Corresponding author

Tel: +82-33-250-6488,

E-mail: jaecho@kangwon.ac.kr
}

(Gracie et al., 1999; Kinne et al., 2000; Michaelsson et al., 1995). The successful resolution of certain severe conditions, therefore, depends on the effective regulation of macrophage functions.

Ginseng-derived saponins have numerous pharmacological efficacies and no in vivo toxicity according to safety tests (Gillis 1997). Nonetheless, the development of biologically-active ginsenosides for food or medicinal purposes is limited and unqualified for patent status, since the components are widely known. Because of the stated limits of ginseng-derived ginsenosides, we aimed to synthesize novel ginsenoside-originated compounds with improved chemical stability and mass production rate. Given these goals, ginsenoside (G)-Rp1 was prepared on a large scale from crude ginsenosides (e.g., G-Rg5 and GRk1) by means of a reduction with hydrogenation and was verified to be chemically stable (Kumar et al., 2006; Yoo et al., 2008). It was also demonstrated that G-Rp1 displayed ten-fold more potent pharmacological activity in terms of anti-cancer effects, compared with G-Rg3 and G-Rg5 (Kumar et al., 2006; Yoo et al., 2008). Furthermore, this compound is also known to block the production of IL-1 $\beta$ at the translational and transcriptional levels.

In addition to its known activities such as chemoprevention and anti-cancer effect (Cho et al., 2001b) as well 
as inhibition of IL-1 $\beta$ production (Kim et al., 2008, In revision), it is of interest whether this compound can negatively modulate macrophage function. In this study, therefore, we explored regulatory effects of G-Rp1 on functionally activated events in macrophages such as TNF- $\alpha$ production, NO secretion, ROS generation, and phagocytic uptake.

\section{MATERIALS AND METHODS}

\section{Materials}

G-Rp1 (Fig. 1) of $97 \%$ purity and its derivatives (G-Rp2, G-Rp3 and G-Rp4) with more than 97\% purity were prepared using established protocols (Lee et al., 2006). The stock solution of G-Rp1 (20 mM) was prepared using $100 \%$ dimethyl sulfoxide. Theophylline, pentoxifylline, curcumin, 2, 7-dichlorodihydrofluorescein diacetate ( $\mathrm{H}_{2}$ DCFDA), FITC-labeled dextran, ascorbate, and lipopolysaccharide (LPS, E. coli 0111:B4) were purchased from Sigma (St. Louis, MO). PP2, LY294002, and wortmannin were obtained from Calbiochem (La Jolla, CA). Fetal bovine serum (FBS) was obtained from GIBCO (Grand Island, NY). All other chemicals were Sigma grade.

\section{Cell culture}

RAW264.7 cells (the American Type Culture Collection, Rockville, MD) were maintained in complete<smiles>[R20]OC1CCC2(C)C3CC(O)C4C(C(C)CCCC(C)C)CCC4(C)C3CC([R2])C2C1(C)C</smiles>

\begin{tabular}{lll} 
& \multicolumn{1}{c}{$\mathrm{R}_{1}$} & \multicolumn{1}{c}{$\mathrm{R}_{2}$} \\
\hline G-Rp1 & Glc-Glc- & \\
G-Rp2 & Glc- & \\
G-Rp3 & & O-Glc-Rha \\
G-Rp4 & & O-Glc
\end{tabular}

Fig. 1. Chemical structure of ginsenoside (G)-Rp1, G-Rp2, GRp3 and G-Rp4.
RPMI1640 medium (supplemented with $100 \mathrm{U} / \mathrm{ml}$ of penicillin and $100 \mu \mathrm{g} / \mathrm{ml}$ of streptomycin, and $10 \%$ fetal bovine serum).

\section{TNF- $\alpha$ release in vitro}

The modulatory effect of G-Rp1 on TNF- $\alpha$ release was determined as previously described (Cho et al., 2000). RAW264.7 cells $\left(2 \times 10^{6}\right.$ cells $\left./ \mathrm{ml}\right)$ were incubated with LPS and various concentrations of G-Rp1 for $6 \mathrm{~h}$. Supernatants were collected and assayed for TNF- $\alpha$ content using the mouse TNF- $\alpha$ enzyme-liked immunosorbent assay (ELISA) kit (Amersham, Little Chalfont, Buckinghamshire, UK).

\section{MTT assay (colorimetric assay) for measurement of cell viability}

Effect of G-Rp1 on cell viability were determined by conventional MTT assay, as previously reported (Ding et al., 1998).

\section{NO assay}

RAW 264.7 cells were preincubated with or without testing compounds (G-Rp1 and PP2, a Src kinase inhibitor) for $30 \mathrm{~min}$ and continuously activated with LPS $(1 \mu \mathrm{g} /$ $\mathrm{ml})$ for 24 hours. Nitrite determination was carried out using Griess reagent (Hong et al., 2003). The absorbance of the product dye was measured at $540 \mathrm{~nm}$ using an ELISA reader.

\section{Extraction of total RNA and semiquantitative RT- PCR amplification}

The total RNA from the LPS treated-RAW264.7 cells was prepared by adding TRIzol Reagent (Gibco BRL), according to manufacturer's protocol. Semiquantitative RT reactions were conducted using MuLV reverse transcriptase as reported previously (Lee et al., 2006). The primers (Bioneer, Daejeon, Korea) (Table 1) were used as previously reported (Cho et al., 2001a).

\section{Immunoblotting}

Cells $\left(5 \times 10^{6} \mathrm{cells} / \mathrm{ml}\right)$ were lysed in lysis buffer (in $\mathrm{mM}$ :

Table I. Sequences of primers of the investigated genes in a RT-PCR analysis

\begin{tabular}{ccc}
\hline Gene & & \multicolumn{2}{c}{ Primer sequences } \\
\hline \multirow{2}{*}{ iNOS } & F & 5'-CCCTTCCGAAGTTCTGGCAGCAGC-3' \\
& R & 5 '-GGCTGTCAGAGCCTCGTGGCTTTGG-3' \\
GAPDH F & 5'-CACTCACGGCAAATTCAACGGCAC-3' \\
& R & 5'-GACTCCACGACATACTCAGCAC-3' \\
\hline
\end{tabular}


20 TRIS-HCl, pH 7.4, 2 EDTA, 2 EGTA, $50 \beta$-glycerophosphate, 1 sodium orthovanadate, 1 dithiothreitol, $1 \%$ Triton X-100, $10 \%$ glycerol, $10 \mu \mathrm{g} / \mathrm{ml}$ leupeptin, $10 \mu \mathrm{g} / \mathrm{ml}$ aprotinin and $10 \mu \mathrm{g} / \mathrm{ml}$ pepstatin, 1 benzimidine and 2 hydrogen peroxide) for $30 \mathrm{~min}$ rotating at $4^{\circ} \mathrm{C}$. Lysates were clarified by centrifugation at $16,000 \times \mathrm{g}$ for $10 \mathrm{~min}$ at $4^{\circ} \mathrm{C}$. Soluble cell lysates were immunoblotted and total levels of iNOS and $\beta$-actin were visualized as previously reported (Bai et al., 2005).

\section{ROS determination}

The level of intracellular ROS was determined by the change in fluorescence resulting from the oxidation of the fluorescent probe $\mathrm{H}_{2}$ DCFDA (Lee et al., 2006). Briefly, $5 \times 10^{5}$ cells/well were incubated with G-Rp1 for $30 \mathrm{~min}$ and then with LPS $(1 \mu \mathrm{g} / \mathrm{ml})$ for additional $6 \mathrm{~h}$. After final incubating with $50 \mu \mathrm{M}$ of $\mathrm{H}_{2}$ DCFDA for $1 \mathrm{~h}$, intracellular ROS level was determined using flow cytometry.

\section{DPPH assay}

DPPH scavenging activity of G-Rp1 was examined according to the method previously described (Lee et al., 2007). In brief, the reaction mixtures containing various concentrations of G-Rp1 and $100 \mathrm{mM}$ DPPH solution in a 96-well microtiter plate were incubated at $37^{\circ} \mathrm{C}$ for 30 $\mathrm{min}$, and absorbance was measured at $490 \mathrm{~nm}$.

\section{Phagocytic uptake}

To measure the phagocytic activity of RAW264.7 cells, a previously reported method was used with slight modifi-

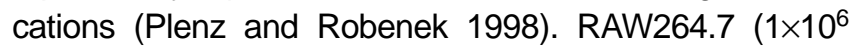
cells $/ \mathrm{ml}$ ) cells were preincubated with or without hydroquinone for $30 \mathrm{~min}$, and further incubated for $6 \mathrm{~h}$. Finally, the cells were further incubated with FITC-dextran $(1 \mathrm{mg} /$ $\mathrm{ml}$ ) for $30 \mathrm{~min}$ at $37^{\circ} \mathrm{C}$. The incubation was stopped by addition of $2 \mathrm{ml}$ of ice-cold PBS, and the cells were washed four times with cold PBS. After fixing the cells with $3.7 \%$ formaldehyde, phagocytic uptake was analyzed on a FACScan (Beckton-Dikinson, San Jose, CA, USA).

\section{Statistical analysis}

A Student's $t$-test and one-way ANOVA were used to determine the statistical significance of differences between values for the various experimental and control groups. Data expressed as means \pm standard errors (SEM) are taken from at least three independent experiments performed in triplicate (Figs. 2A, 2D, 3A, and 3B). The data (Figs. 2B, 2C, 3C and 3D) are representative of three different experiments with similar results. $P$ values
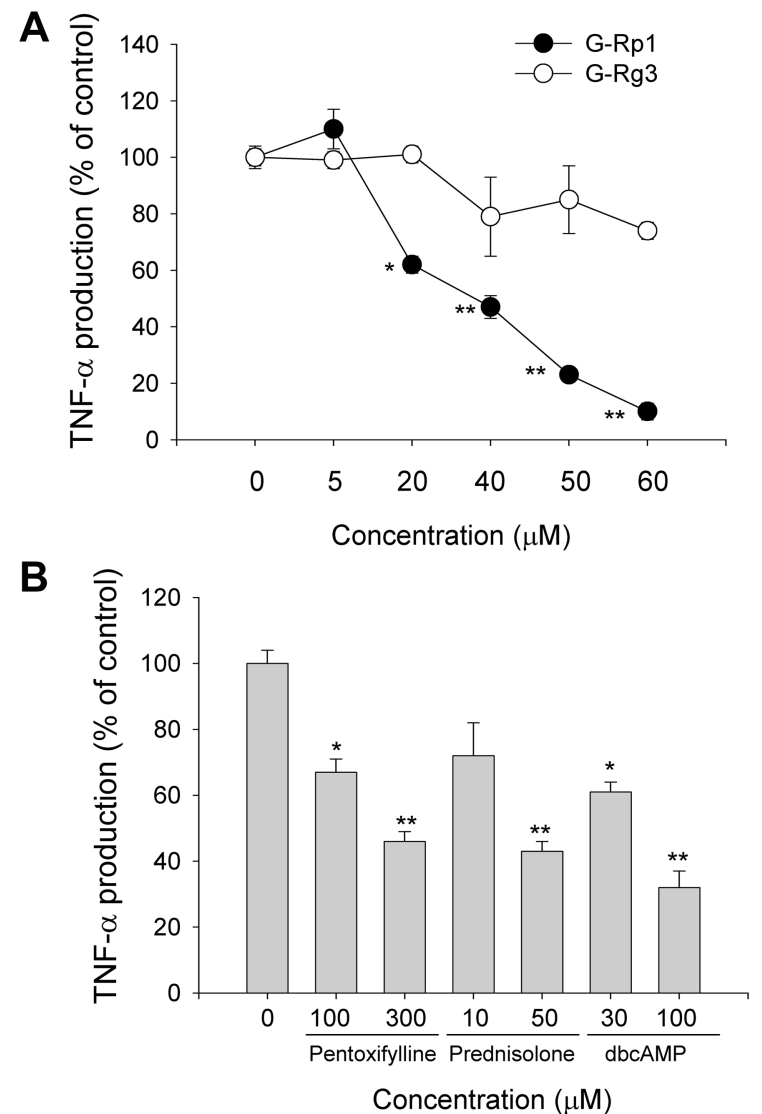

Fig. 2. Effect of G-Rp1 on the production of TNF- $\alpha$ in LPS-activated RAW264.7 cells. (A and B) RAW264.7 cells $\left(2 \times 10^{6}\right.$ cells/ $\mathrm{ml}$ ) were incubated with indicated concentrations of G-Rp1, G$\mathrm{Rg} 3$, and positive drugs (pentoxifylline, prednisolone and dbcAMP) in the presence or absence of LPS $(1 \mu \mathrm{g} / \mathrm{ml})$ for $6 \mathrm{~h}$. Secreted level of TNF- $\alpha$ in culture supernatant was determined by ELISA. ${ }^{*} p<0.05$ and ${ }^{* *} p<0.01$ represent significant difference compared to control.

of 0.05 or less were considered to be statistically significant.

\section{RESULTS AND DISCUSSION}

Acute and chronic inflammation responses are mainly managed by functional activation of macrophages and are regarded as serious conditions at certain states. Popular diseases such as cancer, autoimmune diseases (such as rheumatoid arthritis) and atherosclerosis are thought to be caused by these inflammatory responses (Lee et al., 2008a). To prevent serious diseases, therefore, it is considered that non-toxic and strong immunosuppressive agents should be developed.

Based on these, we prepared novel ginsenoside derivatives from saponins, ethnopharmacologically safe and 
effective principles from Panax ginseng, and found that these compounds blocked the production of IL-1 $\beta$, a proinflammatory cytokine, by suppressing NF-KB activation pathway (Kim et al., 2008, In revision). This finding led us to additionally explore as to whether G-Rp1 was able to negatively modulate total functional activation of macrophage under inflammatory responses.

Our data strongly suggested that G-Rp1 may act as a strong immunosuppressive, anti-inflammatory agent capable of negatively modulating macrophage functions. As Fig. 2A shows, G-Rp1 strongly suppressed production of TNF- $\alpha$, a representative proinflammatory cytokine released from activated macrophages, without altering cell viability (data not shown). In contrast, G-Rg3 did not diminish TNF- $\alpha$ production, suggesting that simple treatment of ginsenoside did not affect cytokine production from LPS-activated macrophages. Positive control drugs (pentoxifylline, prednisolone and dbcAMP) also displayed significant inhibitory activity on TNF- $\alpha$ production (Fig. 2B). G-Rp1 was also found to block IL-1 $\beta$ production at both transcriptional and transcriptional levels (Kim et al., 2008, In revision). The inhibitory activity $\left(\mathrm{IC}_{50}=\right.$ $34.2 \mu \mathrm{M})$ of G-Rp1 on TNF- $\alpha$ production was comparable or higher to other clinically available drugs such as SDZ62-434 $\left(\mathrm{IC}_{50}=42 \mu \mathrm{M}\right)$, davallialactone $\left(\mathrm{IC}_{50}=33\right.$ $\mu \mathrm{M})$, pentoxifylline $\left(\mathrm{IC}_{50}=228 \mu \mathrm{M}\right)$ and theophylline $\left(\mathrm{IC}_{50}\right.$ $=452 \mu \mathrm{M}$ ), as reported previously (Cho et al., 2000; Lee et al., 2008b; Vandana et al., 2006).

Inflammation includes necrotic cell damages induced

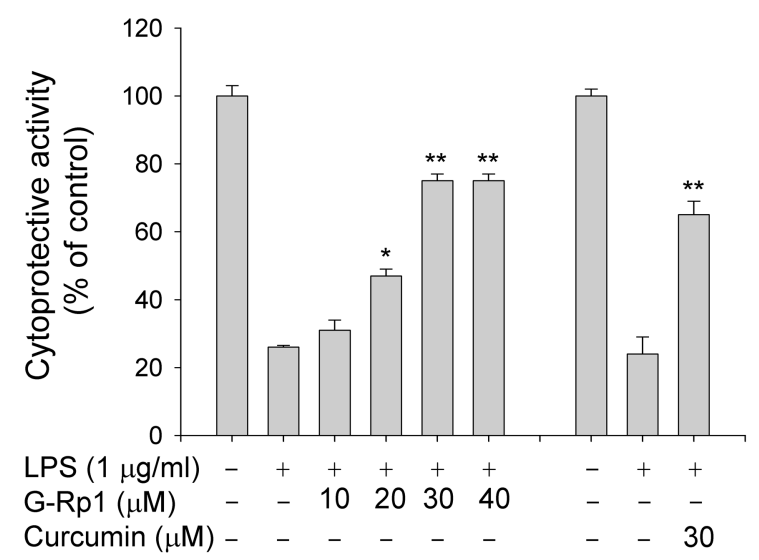

Fig. 3. Cytoprotective effects of G-Rp1 on LPS-induced cell death of RAW 264.7 cells. RAW264.7 cells $\left(1 \times 10^{6}\right)$ were pretreated with various concentrations of G-Rp1 or curcumin in the presence or absence of LPS $(1 \mu \mathrm{g} / \mathrm{ml})$ for $24 \mathrm{~h}$. The viability of cells was measured by MTT assay. * $p<0.05$ and ${ }^{* *} p<0.01$ represent significant difference compared to control (LPS alone). by reactive species such as NO and ROS (Jung et al., 2006). Treatment of RAW264.7 cells with LPS causes cell death of these cells due to the generation of $\mathrm{NO}$ and ROS. Indeed, anti-oxidative agents are reported to protect LPS-induced cell death of RAW264.7 cells (Wang et al., 1984). Therefore, whether G-Rp1 was able to ameliorate cell damage was examined using LPS-treated RAW264.7 cells by MTT assay. As Fig. 3 depicts, this compound dose-dependently abrogated LPS-induced cell death, as shown in the case of curcumin, suggesting that cell death-causing reactive molecules could be suppressed by G-Rp1. Indeed, G-Rp1 strongly inhibited NO production in RAW264.7 cells under LPS stimulation. As Fig. 4 shows, G-Rp1 dose-dependently blocked NO release and at $40 \mu \mathrm{M}$, this compound also down-regulated iNOS protein as well as iNOS mRNA, as shown in the case of IL-1 $\beta$. Similarly, a Src kinase inhibitor, PP2 dose-dependently suppressed NO production in LPS-

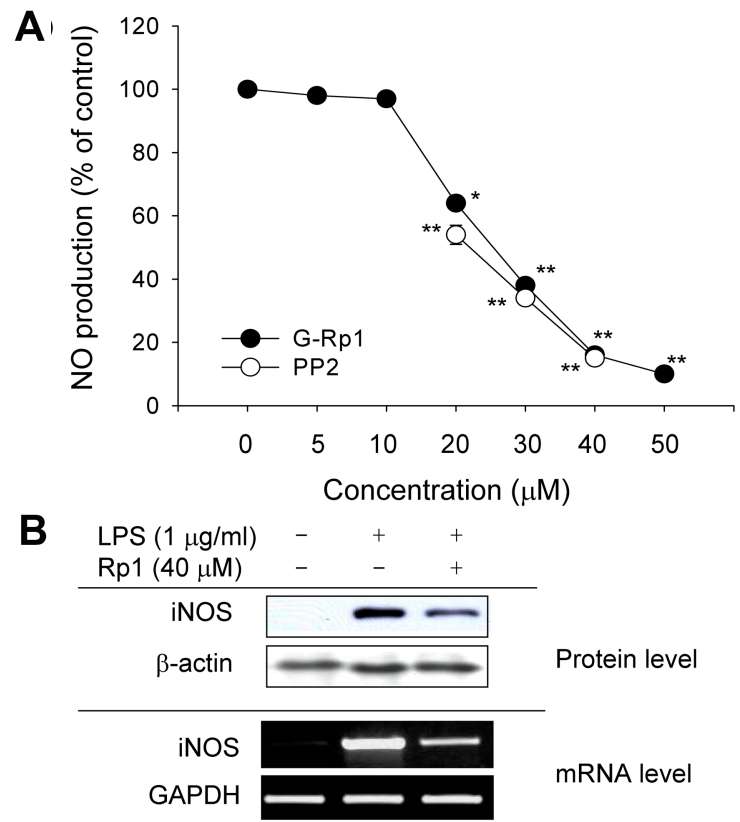

Fig. 4. Effects of G-Rp1 on the production of NO in LPSinduced RAW 264.7 cells or peritoneal macrophages. (A) RAW264.7 cells $\left(1 \times 10^{6}\right)$ were pretreated with various concentrations of G-Rp1 or PP2 in the presence or absence of LPS $(1 \mu \mathrm{g} / \mathrm{ml})$ for $24 \mathrm{~h}$. The level of NO was determined by Griess reagent as described in Materials and Methods. (B) iNOS protein level from G-Rp1-treated RAW264.7 cells activated by LPS was determined by immunoblotting analysis (Upper panel). iNOS mRNA level from G-Rp1-treated RAW264.7 cells activated by LPS was determined by semiquantitative RT-PCR (Lower panel). The results show one representative experiment out of three. ${ }^{*} p<0.05$ and ${ }^{* *} p<0.01$ represent significant difference compared to control. 

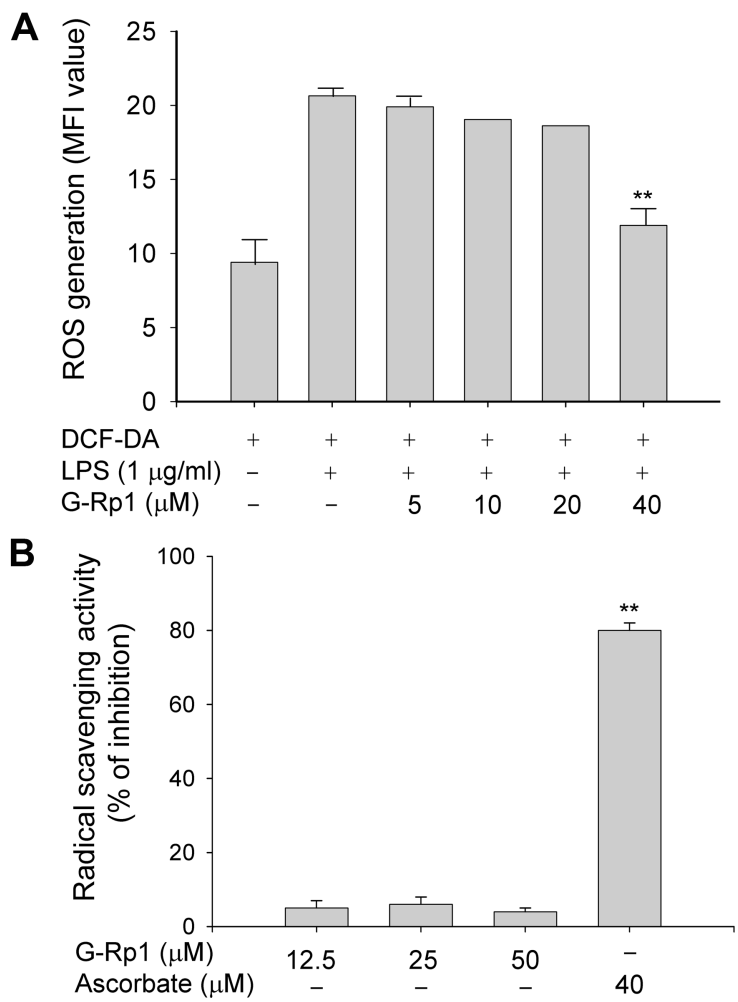

Fig. 5. Effects of G-Rp1 on ROS generation in LPS-induced RAW 264.7 cells. (A) RAW264.7 cells $\left(1 \times 10^{6}\right)$ were pretreated with various concentrations of $\mathrm{G}-\mathrm{Rp} 1$ in the presence or absence of LPS $(1 \mu \mathrm{g} / \mathrm{ml})$ for $30 \mathrm{~min}$. The level of ROS generated was determined by flowcytometric analysis as described in Materials and Methods. (B) Anti-oxidative effects of G-Rp1 and ascorbate were examined by DPPH assay as described in Materials and Methods. ${ }^{* *} p<0.01$ represents significant difference compared to control.

treated RAW264.7 cells (Fig. 4A), as reported previously (Lee et al., 2008, In press).

Scavenging effect of G-Rp1 on ROS generation induced by LPS was also investigated. G-Rp1 significantly blocked ROS generation at $40 \mu \mathrm{M}$ (Fig. 5A). However, since G-Rp1 did not have direct radical scavenging effect, according to DPPH assay (Fig. 5B). Therefore, these results suggest that the neutralizing effect of G-Rp1 at higher concentration seemed to be due to up-regulation of cellular redox components such as glutathione. Meanwhile, standard anti-oxidative drugs, ascorbate and $\alpha$-tocopherol displayed strong radical scavenging activity in both LPS-induced ROS generation and DPPH assays (data not shown).

Since phagocytosis is a representative of inflammatory responses (Wang et al., 1984), regulatory role of G-Rp1 on phagocytic uptake of FITC-dextran was also explored.
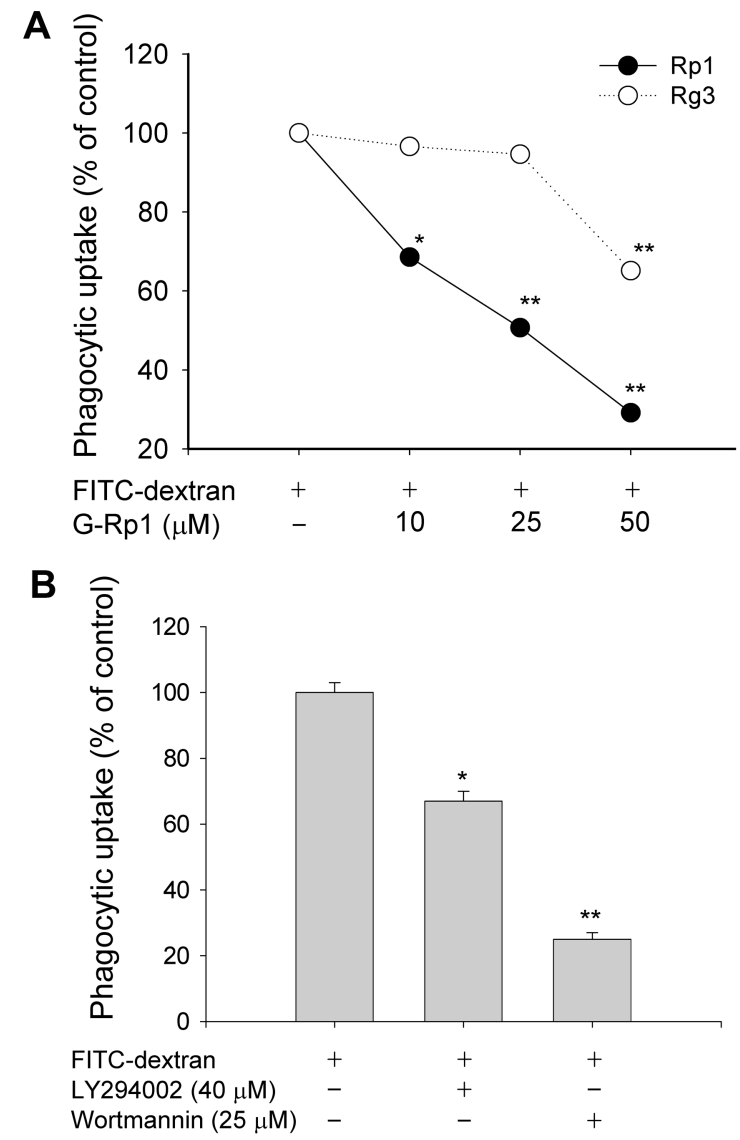

Fig. 6. Effect of G-Rp1 on the phagocytic uptake of FITClabeled dextran. (A and B) RAW264.7 cells $\left(1 \times 10^{6}\right)$ were incubated with in the indicated concentrations of G-Rp1 or positive control drugs (wortmannin and LY294002) in the presence or absence of $1 \mathrm{mg} / \mathrm{ml}$ of FITC-labeled dextran for 30 min. The uptake level of dextran was determined by flow cytometric analysis as described in Materials and Methods. * $p<0.05$ and ${ }^{* *} p<0.01$ represents significant difference compared to control.

As Fig. 6A shows, G-Rp1 dose-dependently suppressed the dextran uptake up to $70 \%$, suggesting that this compound was able to block initial response of macrophage activation. Although we cannot explain exact mechanism of this effect, the inhibition seems to be due to suppressing actin cytoskeleton reorganization. This is possible because 1) G-Rp1 blocked actin polymerization induced by $\beta 1$-integrin ligation in U937 cells (data not shown) and 2) actin polymerization inhibitors such as cytochalasin B have also been reported to block phagocytic uptake (Haberzettl et al., 2007; Miller et al., 2003). Meanwhile, two PI3K inhibitors (wortmannin and LY294002) significantly suppressed the phagocytic uptake of FITC-dextran (Fig. 6B), as reported previously (Choo et al., 2008). 


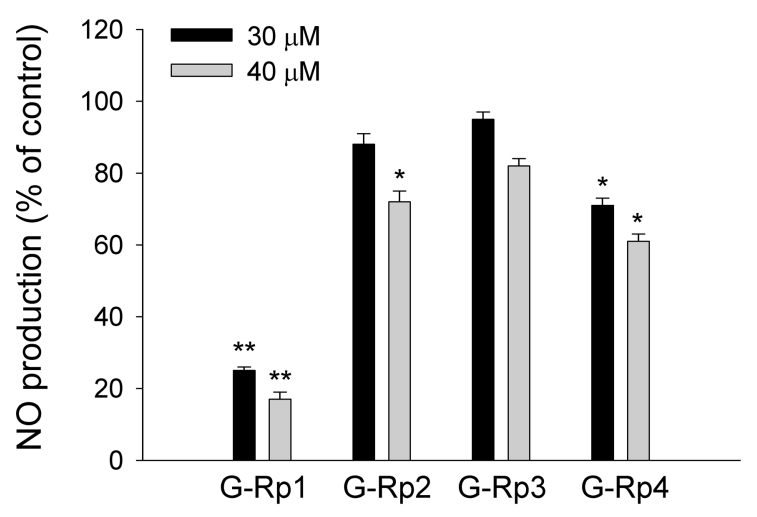

Fig. 7. Structural feature of G-Rp1-mediated inhibition of NO production. RAW264.7 cells $\left(1 \times 10^{6}\right)$ were pretreated with GRp1 or its derivatives (G-Rp2, G-Rp3, and G-Rp4) in the presence or absence of LPS $(1 \mu \mathrm{g} / \mathrm{ml})$ for $24 \mathrm{~h}$. The level of NO was determined by Griess reagent as described in Materials and Methods. ${ }^{*} p<0.05$ and ${ }^{* *} p<0.01$ represents significant difference compared to control.

Recently, immunosuppressive effects of ginsenosides or their metabolites such as compound K, G-Rh1, G-Rb1, G-Rb2, G-Rh2, and 20(S)-protopanaxatriol have been reported. These compounds are found to block NO production, TNF- $\alpha$ release, and $\mathrm{PGE}_{2}$ secretion both at the transcriptional and translational levels (Bae et al., 2006; Cho et al., 2001b; Shin et al., 2006). Interestingly, the inhibitory target of these compounds is regarded to be a series of signaling cascade for NF-KB and AP-1 activation pathways including JNK and protein kinase $A$, but not the activation of glucocorticoid receptor (Bae et al., 2006; Choi et al., 2007). Therefore, we also looked over structural feature of G-Rp1 using its derivatives (Fig. 1). Unlike inhibitory pattern of other anti-inflammatory ginsenosides with simple aglycone structures, a simple form (G-Rp2) of G-Rp1 with single glucose moiety at R1 position displayed weaker activity than G-Rp1 on NO production (Fig. 7). Furthermore, G-Rp3 with no carbohydrate moiety at R1 position and two moieties (Glucose and Rhamnoside) exhibited higher activity than G-Rp4 with single glucose moiety. Finally, carbohydrate moiety at $\mathrm{R} 1$ rather than R2 seems to greatly contribute to the inhibitory activity of G-Rp1. Due to limitation of derivative number, however, we cannot finish full structure-activity relationship study. Further study, therefore, will be followed as soon as we make additional derivatives.

Conclusively, we found that G-Rp1 inhibited TNF- $\alpha$ production, LPS-induced cell cytotoxicity, NO production, ROS generation, and phagocytic uptake from activated
RAW264.7 cells. Preliminary structure-activity relationship study using several G-Rp1 analogs indicated that two carbohydrates at R1 position and no carbohydrate at R2 position were observed to show the highest activity, compared to other structural derivatives. Although the inhibitory activities of G-Rp1 on macrophage functions were not higher, several points that G-Rp1 was known to be safe, and that this compound was orally effective, suggest that G-Rp1 may be beneficial in treating macrophage-mediated immunological diseases.

\section{ACKNOWLEDGEMENTS}

The authors acknowledge Miss JY Lee and Mr. BH Kim for their technical assistances.

\section{REFERENCES}

Bae, E. A., Kim, E. J., Park, J. S., Kim, H. S., Ryu, J. H., and Kim, D. H. (2006). Ginsenosides Rg3 and Rh2 inhibit the activation of AP-1 and protein kinase A pathway in lipopolysaccharide/interferon-gamma-stimulated BV-2 microglial cells. Planta Med. 72, 627-633.

Bai, X. C., Lu, D., Liu, A. L., Zhang, Z. M., Li, X. M., Zou, Z. P., Zeng, W. S., Cheng, B. L. and Luo, S. Q. (2005). Reactive oxygen species stimulates receptor activator of NF-kappaB ligand expression in osteoblast. J. Biol. Chem. 280, 1749717506.

Cho, J. Y., Baik, K. U., Jung, J. H. and Park, M. H. (2000). In vitro anti-inflammatory effects of cynaropicrin, a sesquiterpene lactone, from Saussurea lappa. Eur. J. Pharmacol. 398, 399-407.

Cho, J. Y., Fox, D. A., Horejsi, V., Sagawa, K., Skubitz, K. M., Katz, D. R. and Chain, B. (2001a). The functional interactions between CD98, beta1-integrins, and CD147 in the induction of U937 homotypic aggregation. Blood 98, 374-382.

Cho, J. Y., Yoo, E. S., Baik, K. U., Park, M. H. and Han, B. H. (2001b). In vitro inhibitory effect of protopanaxadiol ginsenosides on tumor necrosis factor (TNF)-alpha production and its modulation by known TNF-alpha antagonists. Planta. Med. 67, 213-218.

Choi, K., Kim, M., Ryu, J. and Choi, C. (2007). Ginsenosides compound $\mathrm{K}$ and $\mathrm{Rh}(2)$ inhibit tumor necrosis factor-alphainduced activation of the NF-kappaB and JNK pathways in human astroglial cells. Neurosci. Lett. 421, 37-41.

Choo, M. K., Sakurai, H., Kim, D. H. and Saiki, I. (2008). A ginseng saponin metabolite suppresses tumor necrosis factoralpha-promoted metastasis by suppressing nuclear factorkappaB signaling in murine colon cancer cells. Oncol. Rep. 19, 595-600.

Ding, M., Zhang, M., Wong, J. L., Rogers, N. E., Ignarro, L. J. and Voskuhl, R. R. (1998). Antisense knockdown of inducible nitric oxide synthase inhibits induction of experimental autoimmune encephalomyelitis in SJL/J mice. J. Immunol. 160, 2560-2564.

Gillis, C. N. (1997). Panax ginseng pharmacology: a nitric oxide 
link? Biochem. Pharmacol. 54, 1-8.

Gracie, J. A., Forsey, R. J., Chan, W. L., Gilmour, A., Leung, B. P., Greer, M. R., Kennedy, K., Carter, R., Wei, X. Q., Xu, D., Field, M., Foulis, A., Liew, F. Y. and Mclnnes, I. B. (1999). A proinflammatory role for IL-18 in rheumatoid arthritis. J. Clin. Invest. 104, 1393-1401.

Haberzettl, P., Duffin, R., Kramer, U., Hohr, D., Schins, R. P., Borm, P. J. and Albrecht, C. (2007). Actin plays a crucial role in the phagocytosis and biological response to respirable quartz particles in macrophages. Arch. Toxicol. 81, 459-470.

Hong, S., Kim, S. H., Rhee, M. H., Kim, A. R., Jung, J. H., Chun, T., Yoo, E. S. and Cho, J. Y. (2003). In vitro anti-inflammatory and pro-aggregative effects of a lipid compound, petrocortyne A, from marine sponges. Naunyn Schmiedebergs Arch. Pharmacol. 368, 448-456.

Jung, C. H., Jun, C. Y., Lee, S., Park, C. H., Cho, K. and Ko, S. G. (2006). Rhus verniciflua stokes extract: radical scavenging activities and protective effects on $\mathrm{H} 2 \mathrm{O} 2$-induced cytotoxicity in macrophage RAW 264.7 cell lines. Biol. Pharm. Bull. 29, 1603-1607.

Kinne, R. W., Brauer, R., Stuhlmuller, B., Palombo-Kinne, E. and Burmester, G. R. (2000). Macrophages in rheumatoid arthritis. Arthritis Res. 2, 189-202.

Kumar, A., Kumar, M., Panwar, M., Samarth, R. M., Park, T. Y., Park, M. H. and Kimura, H. (2006). Evaluation of chemopreventive action of Ginsenoside Rp1. Biofactors 26, 29-43.

Lee, H. J., Hyun, E. A., Yoon, W. J., Kim, B. H., Rhee, M. H., Kang, H. K., Cho, J. Y. and Yoo, E. S. (2006), In vitro antiinflammatory and anti-oxidative effects of Cinnamomum camphora extracts. J. Ethnopharmacol. 103, 208-216.

Lee, J. Y., Rhee, M. H. and Cho, J. Y. (2008a). Novel modulatory effects of SDZ 62-434 on inflammatory events in activated macrophage-like and monocytic cells. Naunyn Schmiedebergs Arch. Pharmacol. 377, 111-124.

Lee, Y. G., Kim, J. Y., Lee, J. Y., Byeon, S. E., Hong, E. K., Lee, J., Rhee, M. H., Park, H. J. and Cho, J. Y. (2007). Regulatory effects of Codonopsis lanceolata on macrophage-mediated immune responses. J. Ethnopharmacol. 112, 180-188.

Lee, Y. G., Lee, W. M., Kim, J. Y., Lee, J. Y., Lee, I. K., Yun, B. S., Rhee, M. H. and Cho, J. Y. (2008b). Src kinase-targeted anti-inflammatory activity of davallialactone from Inonotus xeranticus in lipopolysaccharide-activated RAW264.7 cells. Br. J. Pharmacol. 154, 852-863.

Michaelsson, E., Holmdahl, M., Engstrom, A., Burkhardt, H., Scheynius, A. and Holmdahl, R. (1995). Macrophages, but not dendritic cells, present collagen to T cells. Eur. J. Immunol. 25, 2234-2241.

Miller, Y. I., Worrall, D. S., Funk, C. D., Feramisco, J. R. and Witztum, J. L. (2003). Actin polymerization in macrophages in response to oxidized LDL and apoptotic cells: role of 12/15lipoxygenase and phosphoinositide 3-kinase. Mol. Biol. Cell. 14, 4196-4206.

Park M. H. and Park T. Y. (2005). Novel ginsenoside preparation with anti-cancer activity. PCT/KR2005/117501.

Plenz, G. and Robenek, H. (1998). Monocytes/macrophages in atherosclerosis. Eur. Cytokine. Netw. 9, 701-703.

Shin, Y. W., Bae, E. A., Kim, S. S., Lee, Y. C., Lee, B. Y., and Kim, D. H. (2006). The effects of ginsenoside Re and its metabolite, ginsenoside Rh1, on 12-O-tetradecanoylphorbol 13-acetate- and oxazolone-induced mouse dermatitis models. Planta Med. 72, 376-378.

Vandana, S., Ram, S., llavazhagan, M., Kumar, G. D. and Banerjee, P. K. (2006). Comparative cytoprotective activity of vitamin $\mathrm{C}, \mathrm{E}$ and beta-carotene against chromium induced oxidative stress in murine macrophages. Biomed. Pharmacother. 60, 71-76.

Wang, E., Michl, J., Pfeffer, L. M., Silverstein, S. C. and Tamm, I. (1984). Interferon suppresses pinocytosis but stimulates phagocytosis in mouse peritoneal macrophages: related changes in cytoskeletal organization. J. Cell. Biol. 98, 13281341. 